\title{
Heart rate and longevity
}

\author{
Mario Augusto Paschoal ${ }^{1 *}$ (i)
}

\begin{abstract}
Background: Living longer has been a challenge for science, especially in recent years. There are several lines of research that aim to provide new knowledge that can promote the increase in human longevity. Among these lines, studies on resting heart rate (RHR) have drawn attention because when RHR is maintained at values close to $60 \mathrm{bpm}$, is an important factor associated with greater longevity. Aim: To show that the low RHR is positively related to lower mortality from cardiovascular diseases and diseases caused by other factors. Methods: A threedecade retrospective analysis was performed from the main articles in which the relationship between resting heart rate and longevity was studied. Results: All studies reveal that in healthy people and in patients with certain illnesses, lower resting heart rate values provide greater longevity. Also, studies confirm that the practice of aerobic physical exercises performed regularly and mental relaxation are the most effective procedures to decrease RHR in a non-pharmacological way. The physiologic effect of reducing RHR appears to be an increase in parasympathetic tone, especially in the case of yoga, and a decrease in intrinsic HR by mechanisms not yet been fully understood. Conclusions: With the new results from important studies that confirmed this new possibility of increasing longevity, health professionals should be concerned with paying more attention to monitoring their patients' RHR towards interfering whenever necessary.
\end{abstract}

Keywords: Heart Rate; Longevity; Cardiovascular Health.

\section{How to cite}

Paschoal MA. Heart rate and longevity. Cardiorespir Physiother Crit Care Rehabil. 2021;1:e42591. https://doi.org/10.4322/2675-9977.cpcr.42591

\section{How can the results of this study be used in clinical practice?}

To create and apply protocols for monitoring the population can be relevant in order to detect important changes in the resting heart rate.

Health professionals should pay attention to their patients' resting heart rate values because this may help preserving the health of the patient's heart.

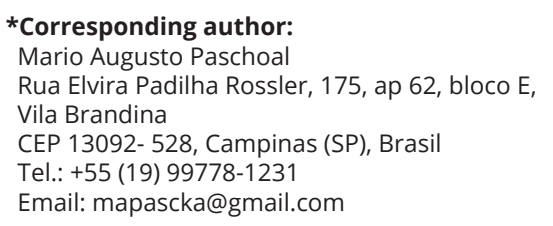




\section{Introduction}

Living longer has been a challenge for the humans since the dawn of civilization. With the scientific and technological advances achieved, mainly from the 19th century to the present, there is no doubt that more people live longer and with a higher quality of life and comfort than has ever been seen in human history ${ }^{1,2}$.

However, would the oldest person of our times be older than the oldest person who lived many years ago? In a hurry and without knowledge, many people would say yes! Nevertheless, longevity is different from life expectancy. Undoubtedly, life expectancy in all regions of our planet has grown in the last century and continues to grow, especially in those countries where it was very low ${ }^{3}$.

However, there is no unanimity that the maximum time that the human being can live has changed significantly throughout the history of humanity, because there is a strong biological barrier limiting the homo sapiens' life at maximum values between 110 and 115 years $^{2}$.

Carmona and Michan ${ }^{4}$ says there is a complex multifactorial process of molecular and cellular decline with aging that affects tissues over time, making the body increasingly fragile and susceptible to disease and death.

Although there are countless speculations and fallacies about increasing longevity, we can say that science is already well aware of the multiple factors involved in prolonging and decreasing life and know how to extract the maximum genetic potential to reach greater longevity.

Diseases related to the cardiovascular system replaced the causes of death, which in the past were hunger, wars and infections, highlighting, in this context, the association of these diseases with the significant increase in global obesity ${ }^{2,5}$.

Since the middle of the last century, the longest-lived people have had the end of their lives determined, generally, by cardiovascular problems or by diseases related to this system $^{6}$. This happens because childhood illnesses were controlled, gastrointestinal infections originating from problems of basic sanitation and poor hygiene have been minimized and major epidemics are quickly combated by the efficient action of science, as we have seen, recently, with the rapid production of vaccines against Covid $19^{7}$. Even cancers have a lower prevalence of causes of death than diseases or disorders linked to the cardiovascular system.

Therefore, although life expectancy is currently higher, we still die from cardiovascular disease. In 2019, according to World Health Organization ${ }^{8}, 17$ million people died from CVDs, representing $32 \%$ of all global deaths. Of these deaths, $85 \%$ were due to heart attack and stroke.

Most of these deaths from CVD were due to ischemic heart disease (IHD) or cerebrovascular disease. So, what to do to control these diseases and extend our years of life?

There are several possibilities being studied by science ${ }^{4}$, but prevention seems to be the most important factor, as it would delay the inexorable appearance of cardiovascular problems present in long-lived people. Yes, prevention seems to be the best answer and in this line of thought, there is a possibility of living longer and healthier, which is the maintenance of low values of resting heart rate (RHR).

RHR or baseline HR, refers to the number of heart beats per minute at rest ${ }^{9}$. The HR is controlled by intrinsic and extrinsic nervous systems. The intrinsic HR, in the absence of any neurohumoral influence, is approximately 100 to $120 \mathrm{bpm}$, and under influence of the extrinsic nervous system, the RHR depends on balance between the tonically active sympathetic and parasympathetic nervous systems. In general, under influence of the intrinsic and extrinsic nervous systems, the RHR will be lower than the HR controlled by intrinsic nervous system only ${ }^{10}$.

The normal range of RHR has traditionally been considered to be between 60 and $100 \mathrm{bpm}$. According to Jensen ${ }^{11}$, one study of U.S. National Health and Nutrition Examination Survey performed between 1999 and 2008, evaluated the distribution of RHR in more than 35,000 individuals without cardiovascular disease. They showed that $71 \mathrm{bpm}$ (with a 2.5 percentile of $49 \mathrm{bpm}$ and a 97.5 percentile of $95 \mathrm{bpm}$ ) was the mean HR in men above age 40. The corresponding number in women above 40 years of age was a mean RHR of $73 \mathrm{bpm}$ with a $95 \%$ range of 53-97 bpm. Overall, there is a gender difference in the magnitude of RHR so that women tend to have higher HR compared to men.

Many years ago, Galeno said "[...] the heart and arteries pulsate with the same rhythm, so that by one of them we can judge them all, and the regular and slow pulse means good health" "12:157.

Really, he was right to say that the heart and all the arteries pulsate with the same rhythm, because we know that in healthy people this is true. However, the assertion that the slow pulse means good health, has promoted, for many years, many discussions due to the lack of scientific confirmation that was relevant and conclusive ${ }^{13}$.

Therefore, it is within this context of how science views the importance of controlling the resting heart rate and its influence on longevity that we seek to explore this subject and reveal the most relevant aspects of this new frontier of knowledge and scientific discussion.

\section{Methods}

A three-decade retrospective analysis was performed from the main articles in which the relationship between resting heart rate and longevity was studied.

\section{Results and discussion}

Alterations in the number of heartbeats reveal metabolic changes, ongoing infectious processes, emotional reactions, dysfunctions or diseases, pain, heat, cold, postural changes, respiration, drug use, and physical exercise, among many other factors ${ }^{2,14}$.

Despite all these important interferences on HR, current studies are concerned with the values of RHR, because it 
seems to be an important indicator of mortality and healthy longevity $1,2,10,15,16$. Large retrospective and prospective epidemiological studies confirmed that RHR is an independent predictor of cardiovascular mortality for all causes in men and women with or without dysfunctional diagnoses ${ }^{15,17-20}$.

Nonetheless, a fast heart rate itself affects the cardiovascular system in multiple ways (it increases ventricular work, myocardial oxygen consumption, endothelial stress, aortic/arterial stiffness and decreases myocardial oxygen supply) which, in turn, may affect survival and longevity. Consequently, higher HR values may contribute and affect life expectancy ${ }^{21}$.

Ventricular work and myocardial oxygen consumption (MVO2) are directly related to heart rate. According to Boudoulas et al..$^{22}$ as heart rate increases, the supply of myocardial oxygen diminishes, because the diastolic interval time during which myocardial blood flow occurs decreases relatively rapidly as heart rate increases.

Another important factor to consider is that the LV systole results in a generation of pressure that travels from the root of the aorta into the peripheral arterial circulation as a pulse wave $^{23}$. The pressure waves with each ventricular systole produce a stress on the arterial endothelial cells. Intrinsic repair mechanisms maintain normal endothelial function when the applied stress is within physiologic limits. When the stress is pathologic the intrinsic repair mechanisms are inadequate to maintain normal endothelium, and thus endothelial damage may occur. This may result in arterial aging and cardiovascular disease. The faster the heart rate, the greater the effect on the endothelium ${ }^{21}$.

How the heart plays its essential role as a pump depends on a double function: contraction force and number of beats. The blood pressure (BP) is related with the myocardium contraction force and is widely studied. All health professional is aware of the organic problems resulting from uncontrolled systemic arterial hypertension. However, in spite of the fact that coronary diseases and dysfunctions, such as heart failure, are treated by means of bradycardic drugs with significant improvements ${ }^{24}$, it is unequivocal that in the daily clinic the numbers of beats do not receive the same attention and importance given to the BP values.

Likewise, less credit is given to the fact that in humans, as with other mammalian homoeothermic animals, there may be a logic regarding a given maximum number of beats predicted for all life.

For Levine $25: 1104$ " [...] the question of whether human life can be extended by cardiac slowing remains moot and most likely will only be resolved by retrospective analyses of large populations, future animal studies and clinical trials using bradycardic therapy". Although there is no evidence, the number of heartbeats for all life of human beings seems to be around three billion.

In mammals, which are the closest to humans, the relationship between the life span of a given animal and the HR values is well-established ${ }^{14,25,26}$. Those animals, whose HR are higher, live less than those with a lower HR. Some types of whale have between 30 and $40 \mathrm{bpm}$ and can live 50 years. A blue whale, for example, which has an average of 10 bpm, can live between 80 and 90 years, while a Wistar rat, which has around $300 \mathrm{bpm}$, lives a maximum of three years ${ }^{25}$.

This inverse semi-logarithmic relationship clearly reveals that mammalian animals have a life span limited to values close to 1 billion heartbeats ${ }^{25}$. Obviously, those whose HR is higher live less than those who have a lower HR, as they reach that total heart beats ( 1 billion) earlier (Figure 1).

Although the human being is an exception to the rule and does not follow exactly this semi-logarithmic relationship, the proposed concept that lower RHR leads to more years of life seems to be real and is commented in all well-conducted studies ${ }^{18,27,28}$.

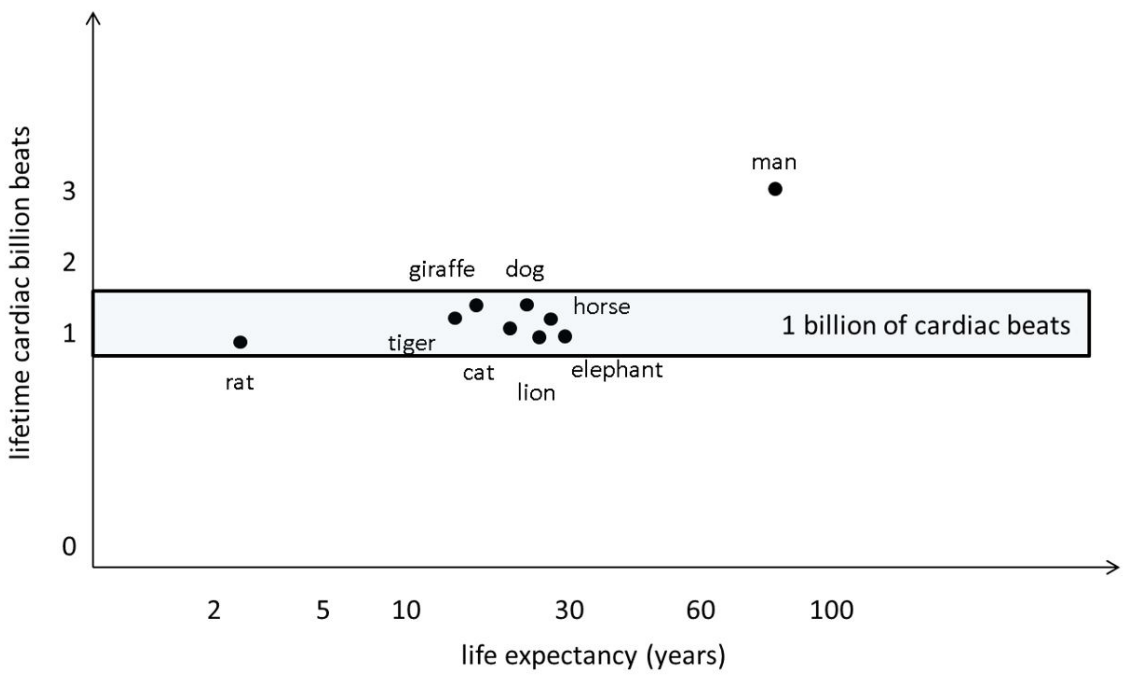

Figure 1. Relationship between lifetime cardiac beats and life expectancy (years). The higher the number of heart rate of each mammal, the lower their life expectancy. Note that the man position is outside of the line of one billion lifetime cardiac beats.

Source: Adapted from Levine ${ }^{25}$. 
Important points that support the above statement are:

a) human beings sleep for $1 / 3$ of their lives and during those times it is essential that they have a low RHR. For example, a 60-year-old person spent about 20 years of their life sleeping. It is essential that throughout that period their heart kept lower HR values so that it has less wear and rests more, contributing to that person's longer life expectancy.

Let us look at this simple calculation: a person who maintains an average HR of $80 \mathrm{bpm}$ during the eight hours of sleep, when compared to another subject who maintains an average HR of $60 \mathrm{bpm}$ in the same eight hours, will have, in just one night, 9.600 heartbeats more than the second subject. Imagine the magnitude of that heart wear in a month or a year and in the long term.

b) the lower RHR is related to caloric restriction, a technique

known as a robust method to increase longevity and delay aging and diseases in animals and humans ${ }^{4}$. Animals and humans when subjected to caloric restriction have a decrease in their energy expenditure and, consequently, require less work from the heart, decreasing RHR. "The life span and heart rate reflects an epiphenomenon in which heart rate is a marker of metabolic rate ${ }^{25: 1104 \%}$.

The first studies carried out to investigate the reliability of statements about the relationship between RHR and greater longevity, were developed in the mid-90s of the last century. At the beginning of the 21 st century and during the first decade of the 2000s, results emerged from robust studies, involving a large sample and monitoring of data for decades.

These studies investigated healthy and sick people who had heart failure, chronic obstructive pulmonary disease (COPD) and acute myocardial infarction (AMI). In all of these studies, there was a significant positive relationship between the lowest RHR and the highest longevity ${ }^{13,17,24,29}$.

Were also analyzed the relationships between the occurrence of death from any cause and deaths that occurred in patients with AMI and the RHR values. Likewise, deaths, in both situations, occurred more prematurely in those people who had higher RHR ${ }^{18}$.

Diaz et al. ${ }^{29}$ studied 24.913 individuals from both sexes who were suspected or had coronary artery disease (CAD), aged between 42 and 55 years, whose clinical data were accompanied for 14.7 years. Regarding these data, they applied the Hazard index (which means the relative risk the occurrence of a certain event as a function of time) to correlate the RHR values the volunteers presented in the consultations over time with the deaths (non-specific and specific cardiovascular causes) that occurred during the study period. They concluded that individuals who always had RHR values below $63 \mathrm{bpm}$ did not show an increase in mortality for both specific and nonspecific conditions.

They also observed that the Hazard index for the relationship between deaths and RHR values increased according to the increment in RHR values (in this index, when the value found is greater than 1, it is understood that there is a significant relationship between cause and effect).

The authors also found that the Hazard index reached a value of 1.3 for the group of individuals whose RHR values were always greater than $82 \mathrm{bpm}$, concluding that deaths from non-specific causes and deaths caused by cardiovascular problems were significantly influenced by the higher RHR values.

Jensen et al. ${ }^{13}$ developed another important work that proved the influence of RHR values for increasing longevity in Denmark. This study involved 5.249 healthy men who were in middle age. The data were collected from 1971 to 2011. Of the initial participants, 3.354 survived until the mid-1980s, and 2.798 of them had enough data for a good RHR analysis.

The authors concluded that the risk of mortality in healthy men increased by $16 \%$ with each $10 \mathrm{bpm}$ increase in RHR . Specifically, they found that men who had an RHR between 71 and $80 \mathrm{bpm}$ were $51 \%$ more likely to die than men with an RHR of $50 \mathrm{bpm}$ or less. They also observed that men with RHR between 81 and 90 bpm were twice as likely to die as those with $50 \mathrm{bpm}$.

Another study ${ }^{17}$, involving patients with COPD, also confirmed the theory of the relationship between the lowest RHR values and the longest life span. This investigation was part of the well-known Copenhagen City Heart Study, which prospectively analyzed data from 16.696 volunteers over 35.3 years ., In that study, 10.986 subjects died during the data analysis period (Figure 2).

Furthermore, in that study,individuals who did not have COPD were compared to those who had COPD. Patients with COPD were allocated into three groups according to the degree of disease severity, using the acronym GOLD (Global Initiative for Chronic Obstructive Lung Disease). The stages range from value I (mildest) to value IV (most severe).

When comparing the RHR values within the group of healthy individuals, those who had median values of $\leq 64 \mathrm{bpm}$ during the long period of the study, lived five years longer than those who had median values of $85 \mathrm{bpm}$ for RHR. These same healthy individuals, with RHR median values of $\leq$ $64 \mathrm{bpm}$, lived 10.5 years longer than those who had COPD with GOLD III and IV and low RHR values. When healthy individuals with median values of $\leq 64 \mathrm{bpm}$ were compared to those of COPD GOLD III and IV with median RHR values greater than $85 \mathrm{bpm}$, the difference was extremely relevant, as patients with COPD lived 16.4 years less.

The evidence regarding negative influence of elevated RHR on cardiovascular system and thus all-cause death is constantly increasing ${ }^{17-19}$. A recent study from Aune et al. ${ }^{30}$ shows that an increase of $10 \mathrm{bpm}$ on RHR increases all-cause mortality in $17 \%$.

In 2018 , Reimers et al. ${ }^{31}$ carried out one of the most important studies with the aim of informing the types of sports and physical exercises that would be most beneficial in reducing RHR values and obtaining the benefits of greater longevity. 


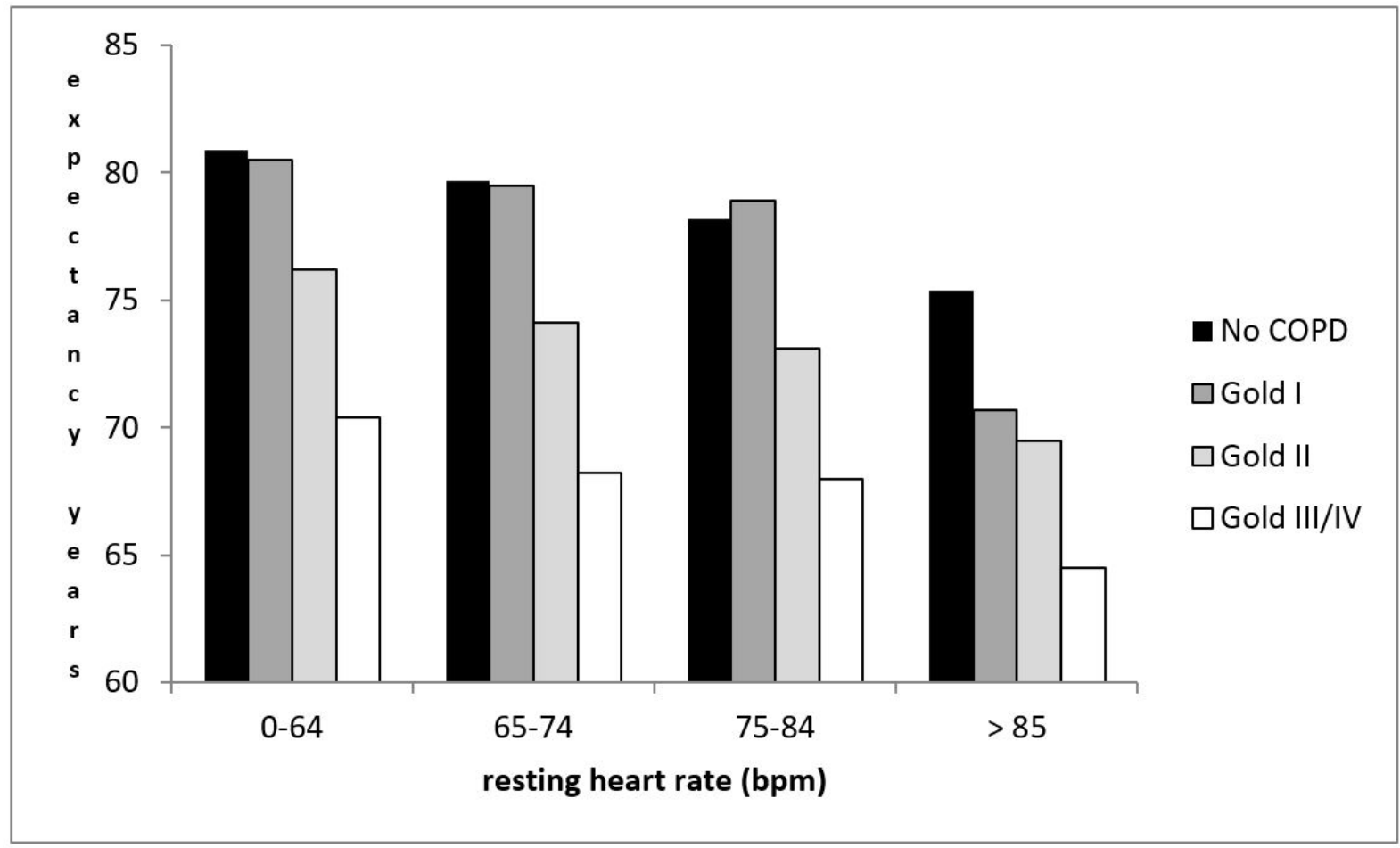

Figure 2. Median values of life expectancy in years by Global Initiative for Chronic Obstructive Lung Disease (GOLD) stage and resting heart rate (RHR).

Source: Adapted from Jensen et al. ${ }^{17}$.

They performed a systematic review and meta-analysis for the identification of controlled trials dealing with the effects of exercise or sports on the RHR in healthy subjects. The literature search analyzed 191 studies from six databases presenting 215 samples fitting the eligibility criteria. One hundred and twenty-one trials examined the effects of endurance training, 43 studies analyzed strength training, 15 combined endurance and strength training, 5 additional school sport programs, 21 yoga, 5 tai chi, 3 qigong, and 2 studies evaluated unspecified types of sports. All types of sports decreased the RHR.

However, only endurance training and yoga significantly decreased the RHR in both sexes. These results reveal two important things: a) aerobic exercises, not necessarily intense, but performed for a long time, are the most effective in reducing RHR; b) the association of physical exercise with mind control is also essential for reducing RHR.

The physiologic effect of reducing RHR after a program of physical exercise seems to be an increase in parasympathetic tone $^{32}$, especially in the case of yoga, lower sympathetic activity ${ }^{33}$ and a decrease in intrinsic HR by mechanisms not yet been fully understood ${ }^{31}$.

Therefore, the decrease of RHR through aerobic exercise depends on a great number of factors, such as regularity, intensity, people's age and healthy or sick volunteers. For example, to confirm what was commented above, we applied 12 sessions of aerobic exercises, performed three times a week, in obese preadolescents ${ }^{34}$ and in young sedentary women $^{35}$. The intensity of obese training was mild (calculated at $65 \%$ of HRsubmax $=195$ - age) during $40 \mathrm{~min}$ a day of training) and for heathy sedentary was moderate $(65 \%$ of HR max during $1 \mathrm{~h}$ a day of training) in order to know if RHR would decrease after the sessions and if this adaptation would be modulated by the autonomic nervous system. Only sedentary volunteers had a significant change in RHR and this occurred due to the increase in cardiac parasympathetic tone, verified through the analysis of heart rate variability (HRV).

For Bonaduce et al. ${ }^{36}$, a lower RHR can also be consequence of various factors related to a training program, including the increase of venous return and systolic volume. With the improvement of the venous return, there is an increase in the systolic volume, and according to Frank-Starling law, when there is an increase in blood volume in its cavities, the heart increases its contraction strength, resulting in cardiac output maintenance with lower HR.

In general, these morpho-functional adaptations occur mainly in individuals with better aerobic conditioning. However, due to biological differences, including genetic ones, it doesn't have an exact time to happen, such as the possible alterations in the cardiac autonomic controls.

\section{Conclusion}

Due to the importance and impact that this issue has caused, it would be extremely relevant to create and apply protocols for monitoring the population, in order to detect important changes in the RHR. In this sense, all health professionals 
should pay attention to their patients' RHR values so that preventive measures are taken in order to preserve, to the maximum, the health of the patient's heart, providing them with the possibility of having greater longevity.

\section{Conflict of interest}

None

\section{References}

1. Reimers CD, Knapp G, Reimers AK. Does physical activity increase life expectancy? A review of the literature. J Aging Res. 2012;2012:243958. http://dx.doi.org/10.1155/2012/243958. PMid:22811911.

2. Paschoal MA. Frequência cardíaca e longevidade: como a que a ciência explica essa relação?. Belo Horizonte: Editora Dialética; 2020. 241 p.

3. Oeppen J, Vaupel JW. Broken limits to life expectancy. Science. 2002;296(5570):1029-31. http://dx.doi.org/10.1126/science.1069675. PMid:12004104.

4. Carmona JJ, Michan S. Biology of healthy aging and longevity. Rev Invest Clin. 2016;68(1):7-16. PMid:27028172.

5. Fontaine KR, Redden DT, Wang C, Westfall AO, Allison DB. Years of life lost due to obesity. JAMA 2003;289(2):187-93.

6. IHME: Institute for Health Metrics and Evaluation. Global Burden of disease - Our world in data 2016. Seattle: IHME; 2016

7. Hassan FA, Minato N, Ishida S, Mohamed Nor N. Social environment determinants of life expectancy in developing countries: a panel data analysis. Glob J Health Sci. 2017;9(5):105-17. http://dx.doi. org/10.5539/gjhs.v9n5p105.

8. WHO: World Health Organization. Cardiovascular diseases. Geneva: WHO; 2019

9. Dyer AR, Persky V, Stamler J, Paul O, Shekelle RB, Berkson $\mathrm{DM}$, et al. Heart rate as a prognostic factor for coronary heart disease and mortality: findings in three Chicago epidemiologic studies Am J Epidemiol. 1980;112(6):736-49. http://dx.doi.org/10.1093/ oxfordjournals.aje.a113046. PMid:7457467.

10. Fagundes JE, Castro I. Valor preditivo da frequência cardíaca em repouso do teste ergométrico na mortalidade. Arq Bras Cardiol. 2010 Dec;95(6):713-9. http://dx.doi.org/10.1590/S0066782X2010005000149. PMid:21109916.

11. Jensen MT, Resting heart rate and relation to disease and longevity: past, present and future. Scan J Clin Laboratory invest. 2019;79(12):108-16.

12. Noah G. O físico - A epopeia de um médico medieval. Rio de Janeiro: Editora Rocco Ltda; 1988.592 p.

13. Jensen MT, Suadicani P, Hein HO, Gyntelberg F. Elevated resting heart rate, physical fitness and all-cause mortality: a 16-year follow-up in the Copenhagen male study. Heart. 2013;99(12):882-7. http://dx.doi. org/10.1136/heartjnl-2012-303375. PMid:23595657.

14. Jiang X, Liu X, Wu S, Zhang GQ, Peng M, Wu Y, et al. Metabolic syndrome is associated with and predicted by resting heart rate: a cross-sectional and longitudinal study. Heart. 2015;101(1):44-9. http:// dx.doi.org/10.1136/heartjnl-2014-305685. PMid:25179964 .

15. Ó Hartaigh B, Gill TM, Shah I, Hughes AD, Deanfield JE, Kuh D, et al Association between resting heart rate across the life course and allcause mortality: Longitudinal findings from the Medical Research Council (MRC) National Survey of Health and Development (NSHD). J Epidemiol Community Health. 2014;68(9):883-9. http://dx.doi. org/10.1136/jech-2014-203940. PMid:24850484.

16. Custodis F, Reil JC, Laufs U, Bohm M. Heart rate: a global target for cardiovascular disease and therapy along the cardiovascular disease continuum. J Cardiol. 2013;62(3):183-7. http://dx.doi.org/10.1016/j. jjcc.2013.02.018. PMid:23806547.

17. Jensen MT, Marott JL, Lange P, Vestbo J, Schnohr P, Nielsen OW, et al. Resting heart rate is a predictor of mortality in COPD. Eur Respir J. 2013;42(2):341-9. http://dx.doi.org/10.1183/09031936.00072212. PMid:23143550.

18. Jouven X, Empana JP, Schwartz PJ, Desnos M, Courbon D, Ducimetière $\mathrm{P}$. Heart-rate profile during exercise as a predictor of sudden death. N Engl J Med. 2005;352(19):1951-8. http://dx.doi. org/10.1056/NEJMoa043012. PMid:15888695.

19. Tverdal A, Hjellvik V, Selmer R. Heart rate and mortality from cardiovascular causes: a 12 year follow-up study of 379,843 men and women aged 40-45 years. Eur Heart J. 2008;29(22):2772-81. http:// dx.doi.org/10.1093/eurheartj/ehn435. PMid:18820324.

20. Mao Q, Huang JF, Lu X, Wu X, Chen J, Cao J, et al. Heart rate influence on incidence of cardiovascular disease among adults in China. Int $\mathrm{J}$ Epidemiol. 2010;39(6):1638-46. http://dx.doi.org/10.1093/ije/dyq119. PMid:20719745.

21. Boudoulas KD, Borer JS, Boudoulas H. Heart Rate, Life Expectancy and the Cardiovascular System: therapeutic Considerations. Cardiology. 2015;132(4):199-212. http://dx.doi.org/10.1159/000435947. PMid:26305771.

22. Boudoulas H, Rittgers SE, Lewis RP, Leier CV, Weissler AM. Changes in diastolic time with various pharmacologic agents: implication for myocardial perfusion. Circulation. 1979;60(1):164-9. http://dx.doi. org/10.1161/01.CIR.60.1.164. PMid:376175.

23. Nichols WW, O'Rourke MF, Vlachopoulos C, editors. McDonald's blood flow in arteries: theoretical, experimental and clinical principles. 6th ed. London, Hoder Arnold; 2011.

24. Böhm M, Reil JC, Deedwania P, Kim JB, Borer JS. Resting heart rate: indicator and emerging risk factor in cardiovascular disease. Am J Med. 2015;128(3):219-28. http://dx.doi.org/10.1016/j.amjmed.2014.09.016. PMid:25447617.

25. Levine HJ. Rest heart rate and life expectancy. J Am Coll Cardiol. 1997;30(4):1104-6. PMid:9316546.

26. Poirier P. Exercise, heart rate variability, and longevity - The Cocoon Mystery? Circulation. 2014;129(21):2085-7. http://dx.doi.org/10.1161/ CIRCULATIONAHA.114.009778. PMid:24799512.

27. Zhang GQ, Zhang W. Heart rate, lifespan, and mortality risk. Ageing Res Rev. 2009;8(1):52-60. http://dx.doi.org/10.1016/j.arr.2008.10.001. PMid:19022405.

28. Palatini P. Elevated heart rate: a "new" cardiovascular risk factor? Prog Cardiovasc Dis. 2009;52(1):1-5. http://dx.doi.org/10.1016/j. pcad.2009.06.001. PMid:19615486.

29. Diaz A, Bourassa MG, Guertin MC, Tardif JC. Long-term prognostic value of resting heart rate in patients with suspected or proven coronary artery disease. Eur Heart J. 2005;26(10):967-74. http://dx.doi. org/10.1093/eurheartj/ehi190. PMid:15774493.

30. Aune D, Sen A, o'Hartaigh B, Janszky I, Romundstad PR, Tonstad $\mathrm{S}$, et al. Resting heart rate and the risk of cardiovascular disease, total cancer, and all-cause mortality: A systematic review and dose-response meta-analysis of prospective studies. Nutr Metab Cardiovasc Dis. 2017;27(6):504-17. http://dx.doi.org/10.1016/j.numecd.2017.04.004. PMid:28552551.

31. Reimers AK, Knapp G, Reimers CD. Effects of exercise on the resting heart rate: a systematic review and meta-analysis of interventional studies. J Clin Med. 2018;7(12):503. http://dx.doi.org/10.3390/ jcm7120503. PMid:30513777.

32. Ueno LM, Hamada T, Moritani T. Cardiac autonomic nervous activities and cardiorespiratory fitness in older men. J Gerontol A Biol Sci Med Sci. 2002;57(9):M605-10. http://dx.doi.org/10.1093/ gerona/57.9.M605. PMid:12196499. 
33. Chacon-Mikahil MPT, Forti VAM, Catai AM, Szrajer JS, Golfetti $\mathrm{R}$, Martins LEB, et al. Cardiorespiratory adaptations induced by aerobic training in middle-aged men: the importance of a decrease in sympathetic stimulation for the contribution of dynamic exercise tachycardia. Braz J Med Biol Res. 1998;31(5):705-12. http://dx.doi. org/10.1590/S0100-879X1998000500016. PMid:9698778.

34. Paschoal MA, Neves FB, Donato BS. Frequência cardíaca e modulação autonômica do coração de pré-adolescentes obesos antes, durante e após curto programa de treinamento aeróbio. Rev Cienc Méd. 2018;27(3):125-33.
35. Brigliador GM, Paschoal MA. Modulação autonômica cardíaca durante exercício dinâmico submáximo estável (EDSE), antes e após programa de treinamento aeróbio de curta duração. In: Anais do XVII Encontro de Iniciação Científica; 2012; Campinas. Campinas: PUC Campinas, 2012.

36. Bonaduce D, Petretta M, Cavallaro V, Apicella C, Ianniciello A, Romano M, et al. Intensive training and cardiac autonomic control in high level athletes. Med Sci Sports Exerc. 1998;30(5):691-6. http:// dx.doi.org/10.1097/00005768-199805000-00008. PMid:9588610. 


\section{Authors' information}

\section{Mario Augusto Paschoal}

Graduate in Physical Education ITE - Bauru - SP - Brazil Graduate in Physiotherapy-PUC Campinas - SP - Brazil Master in Physical Education - UNICAMP - SP - Brazil PhD in Exercise Physiology - UNICAMP - SP Brazil. Professor Titular of Cardiorespiratory Physiotherapy - Faculty of Physiotherapy PUC Campinas - retired - Brazil. Leader of research group during 20 years PUC Campinas_SP - Brazil 